\title{
POLITICAL TRUST IN PREDICTING READINESS TO COMPLY WITH GOVERNMENTAL RESTRICTIONS DURING COVID-19 PANDEMIC
}

\author{
Ivars Austers, Girts Dimdins, Veronika Leja, Viktorija Gaina \\ University of Latvia, Latvia
}

\begin{abstract}
In the present paper, we try to answer the question of what makes a citizen to comply to health behaviour guidelines by comparing trust in government and past behaviour as predictors of COVID-19 pandemic restrictions. Through an online study of 316 respondents, we found that the judgment of government (indirectly, in terms of positive evaluation of government actions during COVID-19) does play an important role in the ratings of the extent to which one will follow restrictions during the pandemic in the future. This variable seems to be a central one in terms of uniting different variables, which predict the restriction following behaviour: an evaluation of the government's competence, benevolence, integrity, general trust in government during the COVID-19, the perceived risk of government actions concerning oneself and one's family, as well as with respect to the evaluation of future economic prospects.
\end{abstract}

Keywords: COVID-19 pandemic, political trust, risk-mitigating behaviour.

\section{Introduction}

In terms of following health behaviour guidelines, what makes a person a good citizen during the COVID-19 pandemic? Is it past behaviour (or habit)? Or, is it trust in the government and its policies? In the present paper, we try to answer this question by comparing trust in government and past behaviour as predictors of following behavioural restrictions during COVID-19 pandemic. One might follow one's usual route of actions, a habit may have established during an early stage of the COVID-19 pandemic, or a person may continue to follow a habitual pattern of action. As Ouellette and Wood (1998) put it, "well-practised behaviours in constant contexts recur because the processing that initiates and controls their performance becomes automatic" (p. 54). Studies during the COVID-19 pandemic have also demonstrated a set of variables, like perceived risk during the pandemic, subjective evaluation of economic well-being, and 
demographic variables (see below for a brief review). The present study was designed to determine the extent political trust in government and positive evaluation of government action during the COVID-19 pandemic together with one's previous behaviour plays in explaining the predicted future restriction following behaviour of individuals during the COVID-19 pandemic.

For the needs of the present study, we define political trust as "a summary judgment that the [political] system is responsive, and will do what is right even in the absence of constant scrutiny" (Miller \& Listhaug, 1990, p. 358). Several empirical studies have demonstrated that political trust predicts citizens' desirable behaviours, e. g., paying taxes (Alm \& Torgler, 2006), or engaging in collective restraint in case of social dilemmas (Tyler \& Degoey, 1995). Political trust also relates to one's willingness to support civil liberties (Davis \& Silver, 2004). On the negative side, it has been shown that a lack of political trust promotes populist voting behaviour (Hetherington, 1999). The aim of the present study is to find the extent to which political trust may facilitate epidemiologically sound behaviour during the COVID-19 crisis, particularly the readiness to engage in COVID-19 restrictive behaviours.

In line with Rudolph (Rudolph, 2017; Rudolph \& Popp, 2009), we assumed that political trust might act as both a simplifier of the decision process and as a provider of confidence for judgments under conditions of risk, and the policy in question may (or may not) be perceived as leading to desirable outcomes. During the COVID-19 pandemic, people that trust government would be more willing to engage in behaviour that may mitigate the pandemic, like following behavioural restrictions. This was the first prediction for our study.

Following the previous studies on trust in an institution, we choose four basic dimensions of trust: the perceived benevolence, competence, integrity (e. g., Grimmelikhuijsen \& Meijer, 2014, Porat et al., 2020), and the associated risk (Herian et al., 2014). We expected that during the COVID-19 pandemic, the readiness to comply to restrictions would be positively correlated to the evaluation of governmental actions; specifically, these actions have to be perceived as being benevolent, competent, and to be following the principles of integrity (Porat et al., 2020). We also know that the generalized character of political trust in case of trust in one institution (government in case of our study) or the public administration in general, extends to the related policies (Christensen \& Lægreid, 2005). Thus, we expected that trust in the public administration system would be positively correlated to the readiness to behave in accordance with COVID-19 restrictions. 
In addition, based on previous findings we predicted that the perceived risk of government policy relating to oneself and one's family will be negatively correlated to behavioural restrictions promoted by the respective policy (Herian et al., 2014).

Besides those predictions, we had a set of others as well. It has been demonstrated that the world economy has been influenced by the spread of the pandemic and the related restrictive measures (Hossain et al., 2020). In addition, Zazher and Rudolph (2020) have demonstrated that subjective well-being (including measures of economic well-being) relates to efficient modes of coping behaviour during the pandemic. Thus, we expected that there would be a positive correlation between the predicted following COVID-19 restrictions and the subjective evaluation of the current economic situation. It has been demonstrated that optimism is related to predicted following COVID-19 restrictions (Jovančević \& Milićević, 2020), consequently we expected that there would be a positive correlation between the predicted following COVID-19 restrictions and the economic situation that one expected in the future. In addition, we predicted that susceptibility to COVID-19 would correlate positively to one's readiness to follow COVID-19 restrictions since there have been similar findings during the COVID-19 pandemic (Nowak et al., 2020). Another variable found to predict predisposition to follow restrictions is gender. Galasso et. al (2020), in a cross-cultural study of eight countries, found that females are generally more prone to following patterns of risk-mitigating behaviour. Thus, the same pattern also formed a prediction for our study. As studies have demonstrated, age also predicts engagement in protective behaviour against COVID-19 - it declines with age (Fisher et al., 2020, Pasion et al., 2020), hence, we predicted that age would correlate negatively with following the restrictions.

\section{Method}

\section{Participants}

A total of 316 respondents $(75.5 \%$ females, mean age $=36.55$, $S D=11.64$ ) participated in the survey. We used the QuestionPro platform to collect data in an online survey. Question Pro is one of the leading data collection platforms for scientific surveys. The participants were recruited via Facebook.com, since our goal was to to test a set of correlational hypotheses not a representative sample (an almost impossible goal in case of collecting data on social networks), our goal was to obtain data of a sufficient variability. This goal is achievable by using a convenience sampling technique on social networks (Roberts, 2014). The data collection took place in May 2020, during the end of the first wave of the COVID-19 epidemic. 


\section{Measures}

The study was conducted in Latvia, and the current government of Latvia was the target for the ratings. The measures were made on rating scales of different length (from 5 to 11 points), however, since the study is correlational in its essence, we sticked to the response scales which have had desmostrated a good variability in previous studies (Dimdins et al., 2019, Gaina et al., 2020). Also, for the sake of rising reliability of the measures, for some variables we used multiple items (like "The government is skilful in its job responsibilities" and "The government is competent (they have the skills and knowledge needed for the job)" for measuring government's competence. For the sake of readability all the questions are presented in Table 1. A more detailed explanation of the measures is given in the next sections.

Following COVID-19 restrictions. We operationalized predicted following government's restrictions by asking respondents to rate their agreement with the question "To what extent will you comply with the government's restrictions in the coming month?" on a seven-point scale, anchored at "not at all" (1) and "completely" (7). We had a single-item measure for past risk-mitigating behaviour: "How would you rate the extent to which you have complied with the government's restrictions so far during the COVID-19 pandemic?" with the same rating scale as for predicted behaviour.

Ratings of the government. For all the questions, a seven-point scale was used. It extended from "not at all" (1) to "completely" (7). A single question was asked to measure trust in government: "To what extent do you generally trust or distrust the government at this time during the COVID-19 pandemic?" Two questions measured the benevolence of government: "The government cares about the well-being of the people of Latvia" and "The government is ready to work selflessly for the benefit of Latvian voters" (Cronbach's alpha $=.87$ ). Two questions measured the competence of the government during the COVID-19 pandemic: "The government is skilful in its job responsibilities" and "The government is competent (they have the skills and knowledge needed for the job)" (Cronbach's alpha = .95). Two questions measured the integrity of the government: "The government is honest" and "The government is consistent in its words and deeds" (Cronbach's alpha $=.87$ ). We also measured the extent to which the respondents agreed with the statement that "Government action puts you and your family at risk, facilitates a sense of instability".

Three items measured the evaluation of the government's actions during the COVID-19 pandemic (informing society, introducing restrictions, and helping, which had to be assessed on a seven-point scale from "the government's action is entirely inappropriate to the situation" (1) to "the government's action is entirely appropriate to the situation" (7) (Cronbach's alpha $=.84)$. 
Table 1. Questionnaire items

\begin{tabular}{|c|c|c|}
\hline $\begin{array}{l}\text { Dependent } \\
\text { variable }\end{array}$ & $\begin{array}{l}\text { Independent variables (questionnaire } \\
\text { items) }\end{array}$ & $\begin{array}{l}\text { Independent } \\
\text { variables (indices) }\end{array}$ \\
\hline \multirow{11}{*}{$\begin{array}{l}\text { To what extent will } \\
\text { you comply with } \\
\text { the government's } \\
\text { restrictions in the } \\
\text { coming month? }\end{array}$} & $\begin{array}{l}\text { How would you rate the extent to } \\
\text { which you have complied with the } \\
\text { government's restrictions so far during } \\
\text { the COVID-19 pandemic? }\end{array}$ & \\
\hline & $\begin{array}{l}\text { To what extent do you generally trust } \\
\text { or distrust the government at this time } \\
\text { during the COVID-19 pandemic? }\end{array}$ & \\
\hline & $\begin{array}{l}\text { The government cares about the well- } \\
\text { being of the people of Latvia } \\
\text { The government is ready to work } \\
\text { selflessly for the benefit of Latvian } \\
\text { voters }\end{array}$ & $\begin{array}{l}\text { Benevolence of the } \\
\text { government }\end{array}$ \\
\hline & $\begin{array}{l}\text { The government is skilful in its job } \\
\text { responsibilities } \\
\text { The government is competent (they } \\
\text { have the skills and knowledge needed } \\
\text { for the job) }\end{array}$ & $\begin{array}{l}\text { Competence of the } \\
\text { government during } \\
\text { the COVID-19 } \\
\text { pandemic }\end{array}$ \\
\hline & $\begin{array}{l}\text { The government is honest } \\
\text { The government is consistent in its } \\
\text { words and deeds }\end{array}$ & $\begin{array}{l}\text { Integrity of the } \\
\text { government }\end{array}$ \\
\hline & $\begin{array}{l}\text { During the COVID- } 19 \text { pandemic the } \\
\text { government's actions were appropriate } \\
\text { with respect to: } \\
\text { informing society, introducing } \\
\text { restrictions, and helping }\end{array}$ & $\begin{array}{l}\text { Evaluation of the } \\
\text { government's } \\
\text { actions during } \\
\text { the COVID-19 } \\
\text { pandemic } \\
\end{array}$ \\
\hline & $\begin{array}{l}\text { To what extent do you trust or do not } \\
\text { trust the public administration system of } \\
\text { the Republic of Latvia as a whole? }\end{array}$ & \\
\hline & $\begin{array}{l}\text { Thinking about yourself now, how likely } \\
\text { are you to get COVID-19 yourself? }\end{array}$ & \\
\hline & $\begin{array}{l}\text { How would you assess the current } \\
\text { economic situation in Latvia? }\end{array}$ & \\
\hline & $\begin{array}{l}\text { How would you forecast the economic } \\
\text { situation in Latvia in a year? }\end{array}$ & \\
\hline & $\begin{array}{l}\text { Have you had a positive COVID-19 test } \\
\text { (a medically confirmed diagnosis of this } \\
\text { disease)? }\end{array}$ & \\
\hline
\end{tabular}

A related yet more general question was asked about one's trust in Latvian public administration system: "To what extent do you trust or do not trust the public administration system of the Republic of Latvia as a whole?" The answers were given on a five-point scale ranging from 1 - "do not trust" to 5 "completely trust". 
Subjective experience. A single question measured the perceived risk of infection: "Thinking about yourself now, how likely are you to get COVID-19 yourself?" with a rating scale from 1 "definitely will not get" to 10 "definitely will get". The evaluation of the current and the predicted economic situation was measured by two questions: "How would you assess the current economic situation in Latvia?" and "How would you forecast the economic situation in Latvia in a year?" with ratings on a scale from -5 to 5 , where "-5" means "very bad" and "5" means "very good". We also asked a single question about an experience with COVID-19 patients: "Have any of your relatives or friends tested positive for COVID-19 (a medically confirmed diagnosis of the disease)?" as well as "Have you had apositive COVID-19 test (a medically confirmed diagnosis of this disease)?". (Since none of the respondents gave a positive answer to the last question, we excluded this variable from the remaining analysis.)

\section{Results}

Means, standard deviations and intercorrelations of the study variables are presented in Table 1 . The majority of the predicted correlations except for four were confirmed. Three of those, which were not confirmed, were not statistically significant (familiarity with a COVID-19 positive person, risk of getting COVID-19, and predicted economic development), while another was correlated in the opposite direction to that predicted - there was a positive correlation of age to the predicted extent of following COVID-19 restrictions.

We regressed all the variables, which correlated to the predicted readiness to engage in mitigating behaviour in the future on this variable to determine the relative degree of the extent, to which each variable explains the predicted following of the restrictions.

We used a forward stepwise OLS linear regression. The computation of the model ended in two steps. There were two positive predictions: those who were already following restrictions were more ready to follow this pattern of behaviour in the future as well, and those evaluating government actions during the COVID-19 epidemic more positively were ready to follow COVID-19 to a greater extent in the future as well. The regression model explained fifty-nine percent of the variance in the dependent variable can be explained by the explanatory variables. This amount is generally considered to be a good fit of the model (Allison, 1999). 


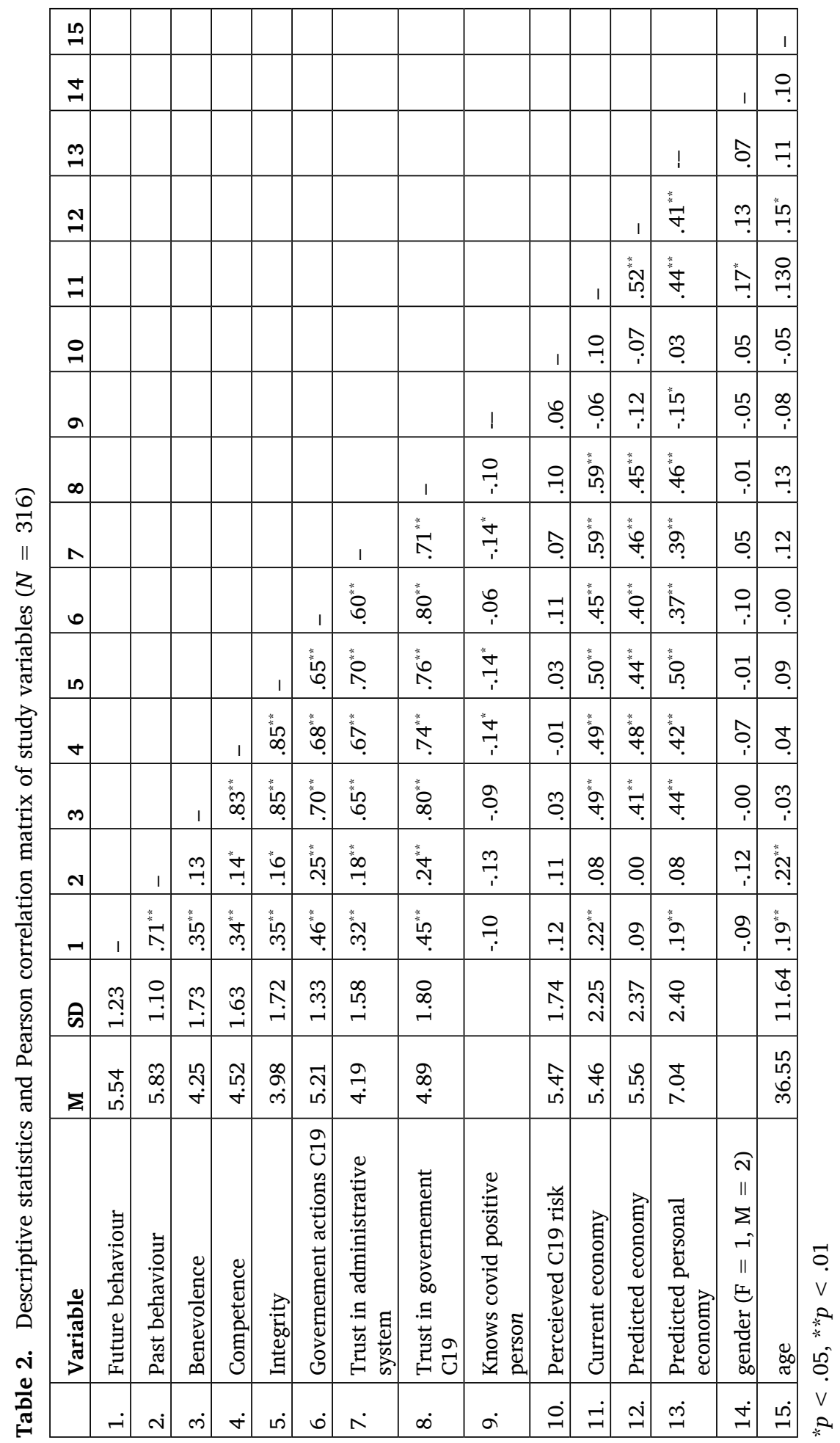


Table 3. Summary of regression (forward stepwise) analysis

\begin{tabular}{|l|l|l|l|l|l|}
\hline Model & Predictor & & & beta & $\boldsymbol{t}$ \\
\hline $1^{1}$ & (Intercept) & 0.95 & 0.31 & & $3.01^{* *}$ \\
\hline & Past bevaviour & 0.79 & 0.05 & .72 & $14.90^{* * *}$ \\
\hline $2^{2}$ & (Intercept) & 0.07 & 0.32 & & -.21 \\
\hline & Past behaviour & 0.71 & 0.05 & .64 & $13.91 \% * *$ \\
\hline & Governement actions C19 & 0.26 & 0.04 & .28 & $6.12^{* * *}$ \\
\hline
\end{tabular}

Dependent variable: agreement to the question "To what extent will you comply with the government's restrictions in the coming month?"

$* * * p<.001 * * p<.01$

${ }^{1} R^{2}=.52, F=(1,207)=221.91, p<.001$

${ }^{2} R^{2}=.59, F=(1,206)=149.28, p<.001$

\section{Discussion}

The results confirmed a majority of predicted correlations. However, there were four that were not confirmed. The predicted extent of following COVID-19 restrictions did not correlate to (1) familiarity with a COVID-19 positive person, (2) the perceived susceptibility to COVID-19, (3) the economic situation that one expected in the future, as well as (4) no gender differences were found. A variable that correlated in the opposite direction of the prediction was age - it correlated positively to the predicted extent of following government's restrictions. This contradicts the pattern found in other studies (e. g., Fisher et al., 2020; Pasion et al., 2020), showing that engagement in protective behaviours declines with age. It seems that our data generally followed inverted-U pattern across respondents. Age (as described in Duell et al., 2017) in this respect would be that by getting older, one gets more rational since an older person is exposed to a greater extent of COVID-19 risk and therefore expects to act in accordance with this level of risk. Because there were very few older respondents, we got only one half of the generally found $U$ pattern in our data. There were no gender differences in willingness to follow risk-mitigating behaviour either. This contradicts the results from other countries, e. g. Galasso et al. (2020) from eight countries, where females scored higher in following patterns of behavioural restrictions. Our study seems to be in line with the few studies where gender differences are less expressed, like the study of Rodriguez-Besteiro et al. (2021) who found very similar behavioural patterns for females and males during COVID-19 pandemic in the sample of Spanish students.

The pattern of regression shows that the judgment of government (in our findings indirectly, in terms of positive evaluation of government actions during COVID-19) does indeed play an important role in the ratings 
of the extent to which one will follow restrictions in the future. This variable seems to be a central one in terms of uniting different variables, which predict following of restrictions: an evaluation of the government's competence, benevolence, integrity, general trust in government during the COVID-19, the perceived risk of government actions concerning oneself and one's family, as well as with respect to the evaluation of future economic prospects. These findings illustrate the importance of a concept closely related to political trust - evaluation of government's actions during the pandemic in ensuring public compliance with COVID-19 restrictions (and public healthcare crises in general). Although our regression model did not isolate trust in government as a separate significant predictor of the readiness to comply with governmental restrictions, the correlation analysis shows that in terms of magnitude of explained variance both trust in government and evaluation of governments actions during the pandemic are similarly related to the readiness to comply. Our findings also demonstrate how past compliance (possibly not related to experienced political trust) is an important predictor of future following governmental restrictions. In case governmental institutions, or any other organizations, are willing to take a long-term approach to increase COVID-19 mitigating practices among citizens, they should take into account building and taking care of trust in public authorities, which, in the case of pandemics or similar crises, may include transparent decision making in combination with clear and consistent communication.

One limitation of the present study is that we did not survey covid-positive persons, by that limiting our findings to covin-negative population. Also, the present paper does not answer the question regarding the source of initial causes for compliant behaviour. There might be several sources, like habit or the following of a social norm. Finding reasons and causes for past compliance behaviour could form another line of research for future studies, and longitudinal studies might be helpful in this respect.

\section{Conclusions}

The main conclusion of the present study is that various aspects of evaluation of the government and its actions in the context of the COVID-19 pandemic (like the perceived benevolence, integrity, and competence of the government, the evaluation of specific governmental actions during the pandemic, and the overall trust in the government) are highly interrelated and may be seen as different expressions of political trust. Hence political trust in government plays a substantial role in predicting readiness to comply with governmental restrictions during the COVID-19 pandemic, adding predictive power to the previous behaviour in following restrictions in the past. 


\section{Acknowledgement}

This research is funded by the Latvian Council of Science, project Developing and testing a psychological model of political trust, project No. lzp-2018/1-0402.

\section{References}

Allison, P. D. (1999). Multiple regression: A primer. Pine Forge Press. https://doi. org/10.1002/sim.895

Alm, J., \& Torgler, B. (2006). Culture differences and tax morale in the United States and in Europe. Journal of Economic Psychology, 27(2), 224-246. https://doi.org/10.1016/j. joep.2005.09.002

Christensen, T., \& Lægreid, P. (2005). Trust in government: The relative importance of service satisfaction, political factors, and demography. Public Performance \& Management Review, 28, 487-511. https://doi:10.2307/3381308

Davis, D. W. \& Silver, B. D. (2004). Civil Liberties vs. Security: Public Opinion in the Context of the Terrorist Attacks on America. American Journal of Political Science, 48(1), pages 28-46, https://doi.org/10.1111/j.0092-5853.2004.00054.x

Dimdins, G., Leja, V., Gaina, V., Austers, I., Muzikante, I. (2019). The role of political trust, perceived self-interest, and perceived societal interests in the evaluation of a policy initiative, Baltic Journal of Psychology, 20, 4-16. https://doi.org/10.22364/bjp.20.01-02

Duell, N., Steinberg, L., Icenogle, G., Chein, J., Chaudhary, N., Di Giunta, L., Dodge, K. A., Fanti, K. A., Lansford, J. E., Oburu, P., Pastorelli, C., Skinner, A. T., Sorbring, E., Tapanya, S., Uribe Tirado, L. M., Alampay, L. P., Al-Hassan, S. M., Takash, H. M. S., Bacchini, D., \& Chang, L. (2017). Age Patterns in Risk Taking Across the World. Journal of Youth and Adolescence, 47(5), 1052-1072. https://doi.org/10.1007/s10964-017-0752-y

Fisher, J., Languilaire, J., Lawthom, R., Nieuwenhuis, R., Petts, R. J., Runswick-Cole, K., et al. (2020). Community, work, and family in times of COVID-19. Community, Work \& Family, 23(3), 247-252. https://doi.org/10.1080/13668803.2020.1756568

Gaina, V., Dimdins, G., Austers, I., Muzikante, I., \& Leja, V. (2020). Testing a Psychological Model of Political Trust. International Journal of Smart Education and Urban Society (IJSEUS), 11(3), 1-10. https://doi.org/10.4018/IJSEUS.2020070101

Galasso, V., Pons, V., Profeta, P., Becher, M., Brouard, S. \& Foucault, M. (2020). Gender differences in COVID-19 related attitudes and behavior: Evidence from a panel survey in eight OECD countries. Proceedings of the National Academy of Sciences, 117(44), 2728527291. https://doi.org/10.1073/pnas.2012520117

Grimmelikhuijsen, S. G., \& Meijer, A. J. (2014). Effects of transparency on the perceived trustworthiness of a government organization: Evidence from an online experiment. Journal of Public Administration Research and Theory, 24(1), 137-157. https:// doi:10.1093/jopart/mus048

Herian, M. N., Shank, N. C., \& Abdel-Monem, T. L. (2014). Trust in government and support for governmental regulation: the case of electronic health records. Health Expectations, 17(6), 784-794. https://doi.org/10.1111/j.1369-7625.2012.00803.x

Hetherington, M. (1999). The Effect of Political Trust on the Presidential Vote, 196896. The American Political Science Review, 93(2), 311-326. https://doi:10.2307/2585398 
Hossain, M. A., Jahid, M. I. K., Hossain, K. M. A., Walton, L. M., Uddin, Z. \& Haque, M. O. (2020). Knowledge, attitudes, and fear of COVID-19 during the Rapid Rise Period in Bangladesh. PLoS ONE, 15(9), 0239646. https://doi.org/10.1371/journal.pone.0239646

Jovančević, A., \& Milićević, N. (2020). Optimism-pessimism, conspiracy theories and general trust as factors contributing to COVID-19 related behavior - A cross-cultural study. Personality and individual differences, 167, 110216. https://doi.org/10.1016/j. paid.2020.110216

Miller, A. H., \& Listhaug, O. (1990). Political parties and confidence in government: A comparison of Norway, Sweden and the United States. British Journal of Political Science, 20, 357-386. https://doi.org/10.1017/S0007123400005883

Nowak, B., Brzóska, P., Piotrowski, J., Sedikides, C., Żemojtel-Piotrowska, M., \& Jonason, P. K. (2020). Adaptive and maladaptive behavior during the COVID-19 pandemic: The roles of Dark Triad traits, collective narcissism, and health beliefs. Personality and individual differences, 167, 110232. https://doi.org/10.1016/j.paid.2020.110232

Ouellette, J. A., \& Wood, W. (1998). Habit and intention in everyday life: The multiple processes by which past behavior predicts future behavior. Psychological Bulletin, 124(1), 54-74. https://doi.org/10.1037/0033-2909.124.1.54

Pasion, R., Paiva, T. O., Fernandes, C., \& Barbosa, F. (2020). The AGE Effect on Protective Behaviors During the COVID-19 Outbreak: Sociodemographic, Perceptions and Psychological Accounts. Frontiers in psychology, 11, 561785. https://doi.org/10.3389/ fpsyg.2020.561785

Porat, T., Nyrup, R., Calvo, R. A., Paudyal, P., \& Ford, E. (2020). Public Health and Risk Communication During COVID-19-Enhancing Psychological Needs to Promote Sustainable Behavior Change. Frontiers in public health, 8, 573397. https://doi. org/10.3389/fpubh.2020.573397

Roberts, K. (2014). Convenience Sampling through Facebook. SAGE Research Methods Cases. https://doi.org/10.4135/978144627305014526836

Rodriguez-Besteiro, S., Tornero-Aguilera, J. F., Fernández-Lucas, J., \& Clemente-Suárez, V. J. (2021). Gender Differences in the COVID-19 Pandemic Risk Perception, Psychology, and Behaviors of Spanish University Students. International Journal of Environmental Research and Public Health, 18(8). https://doi.org/10.3390/ijerph18083908

Rudolph, T. J., \& Popp, E. (2009). Bridging the ideological divide: Trust and support for Social Security Privatization. Political Behavior, 31(3), 331-351. https://doi. org/10.1007/s11109-008-9078-5

Rudolph, T. J. (2017). Political trust as a heuristic. In: Zmerli, S. \& van der Meer, T. W. G. (Eds.) Handbook on Political Trust (pp. 197-211). Edward Elgar Publishing Ltd.. https://doi.org/10.4337/9781782545118.00023

Tyler, T. R., \& Degoey, P. (1995). Collective restraint in social dilemmas: Procedural justice and social identification effects on support for authorities. Journal of Personality and Social Psychology, 69(3), 482-497. https://doi.org/10.1037/0022-3514.69.3.482

Zacher, H., \& Rudolph, C. W. (2020). Individual differences and changes in subjective wellbeing during the early stages of the COVID-19 pandemic. American Psychologist, 76(1), 50-62. https://doi.org/10.1037/amp0000702 